
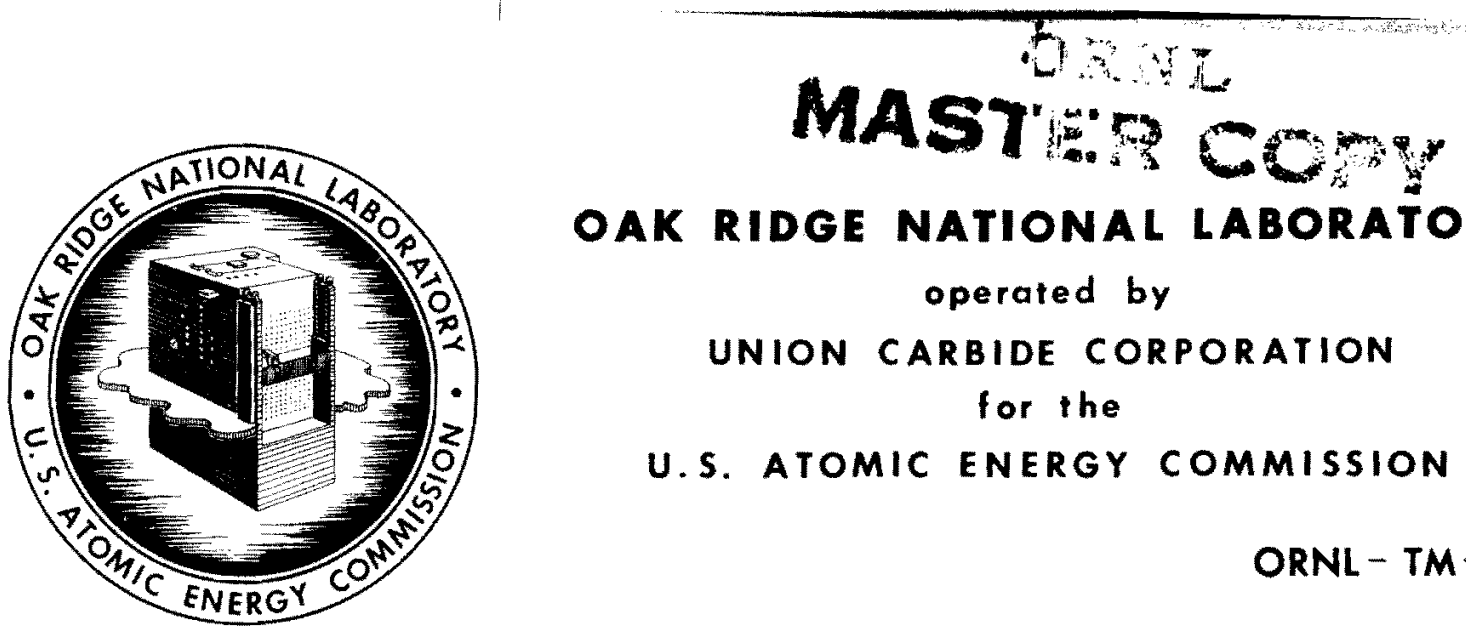

OAK RIDGE NATIONAL LABORATORY

operated by

UNION CARBIDE CORPORATION

UNION

for the

U.S. ATOMIC ENERGY COMMISSION

ORNL-TM- $273+1 / \%$

VAFOR CONTAINMENT IN THE OAK RIDGE RESEARCH REACTOR

F. T. Binford

This document contains information of a preliminary nature and was prepared primarily for internal use at the Oak Ridge National Laboratory. It is subject to revision or correction and therefore does not represent a final report. The information is not to be abstracted, reprinted or otherwise given public dis. semination without the approval of the ORNL potent branch, Legal ond information Control Department. 
This report was prepared as an account of Govermment sponsored work. Neither the United States, nor the Commission, nar any person acting on beholf of the Commission:

A. Makes any waranty or representation, expressed or implied, with respect to the accuracy, completeness, or usefutness of the information contained in this report, ar that the use of any information, apparatus, method, or process disclosed in this report may not intringe privately owned rights; or

B. Assumes any liabilities with respect to the use of, or for damages resulting from the use of any information, apparatus, method, or process disclosed in this report.

As used in the above, "person acting on beholf of the Commission" includes any employee or contractor of the Commission, of employe of such contractor, to the extent that such employe or contractor of the Commission, or employe of such contractor prepares, disseminates, of provides access to, any information pursuant to his employment or controct with the Commission, or his mployment with such contractor. 
ORNL-TM-273

Contract No. W-7405-eng-26

VAPOR CONTAINMENT IN THE OAK RIDGE RESEARCH REACTOR

\author{
F. T. Binford \\ Paper presented at Conference on \\ Light-Water-Moderated Research Reactors \\ June 11-14, 1962 \\ Gatlinburg, Tennessee
}

Date Issued

AUG 231962

OAK RIDGE NATIONAL LABORATORY

Oak Ridge, Tennessee operated by

UNION CARBIDE CORPORATION

for the

U.S. Atomic Energy Commission 


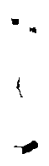

, 


\section{VAPOR CONTAINMENT IN THE OAK RIDGE RESEARCH REACTOR}

F. T. Binford

INTRODUCTION

One of the unique features of the Oak Ridge Research Reactor (ORR $)^{I}$ is the type of containment which has been provided in order to prevent release to the atmosphere of gaseous fission products which may escape as a result of an accident to the reactor. Unlike most other reactor installations, the ORR building is not hermetically sealed for the purpose of retaining the escaped fission products. On the contrary, it is a partially leak-tight building of conventional mill-type construction. Containment is attained by means of a ventilation system which is capable of exhausting air from the building at a rate sufficient to insure that all leakage of air at ground level is into the building. The exhaust air is treated by scrubbing and filtration and is discharged from a large stack at a height and velocity sufficient to guarantee that meteorological dispersion will reduce the resulting concentration of radioactive material to an acceptable level.

The selection of this type of controlled containment depends upon four principal factors:

1. The type of accidents against which protection is sought must be of such a nature that they can be handled by controlled containment. For example, an accident which is accompanied by a large increase in pressure within the building would perhaps exceed the capacity of the exhaust system to prevent leakage from the building. 


\section{$-2-$}

2. The nature and density of the population distribution in the immediate vicinity of the reactor building coupled with the local atmospheric behavior will have an important bearing on the feasibility of controlled containment.

3. All other things being equal, controlled containment offers some advantages over the use of a hermetically sealed building. Such a system offers protection even in the event that considerable mechanical damage has been done to the building. Moreover, it provides a method for readily removing contaminated air from the building in cases of minor accidents. Perhaps the chief disadvantage is that some machinery must be operable during and after the accident for controlled containment to be effective.

4. The relative cost of proviäing stack facilities with sufficient capacity to produce adequate dispersion must be compared with the cost of construction of a hermetically sealed pressure-type building. In the case of the ORR, a suitable stack together with the appropriate ancillary facilities was already available at the reactor site. If containment shielding is required to protect the nearby population from direct radiation from the building, the costs must be examined with respect to the fact that the intensity of radiation from the gaseous fission products within the building may be rapidly reduced through the use of controlled containment.

\section{ORIGINAL DESIGN AND INSTALIATION}

The original ORR containment concept ${ }^{2}$ was based upon the requirement for protection against an accident in which, after continuous operation for a period of 39 days at a power level o1 $20 \mathrm{Mm}$, all of the 
iodines and noble gases are released into the building. In the initial analysis the remaining fjssion products were considered to be nonvolatile and to remain behind. For purposes of computation, it was assumed that this release is instantaneous and that complete and uniform mixing occurs within the building. Previous calculations ${ }^{3}$ had indicated that a discharge rate of I curie per minute from the existing 250 aft stack would, under pessimistic meteorological conditions, produce a maximum ground concentration of $3 \times 10^{-7} \mu \mathrm{c} / \mathrm{cc}$ (decay neglected). Upon taking into consideration the initial isotopic concentrations, the decay constants, and the building-exhaust rate, it is possible to estimate tre total radiation doses received at that point where the highest concentration occurs.

For the conditions stated, it was found that the internal dose due to the inhalation of iodine exceeded what is considered to be an acceptable emergency dose by a factor of about $10^{3}$. To reduce this it was decided to incorporate a packed-tower, caustic scrubber into the system. Such a scrubber, designed to reduce the iodine concentration in the exhaust stream by the requisite amount, was built and installed. Briefly, the containment system as originally installed consisted, first, of the reactor building (Figure l) which is a conventional aluminumhoused, steel-framed, mill-type stmeture having a volume of approximately $800,000 \mathrm{ft}^{3}$. The building is without windows but is penetrated by 12 personnel doors of conventional design and by two 12 - x I6-ft truck doors. In addition, there are twelve openings in the roof which range in area from 1 to $45 \mathrm{sq}$ ft in area. Exhaust fans are mounted in these openings. The air intake and exhaust for the main heating and ventilating system require thres other large openings in the building 
$-4-$

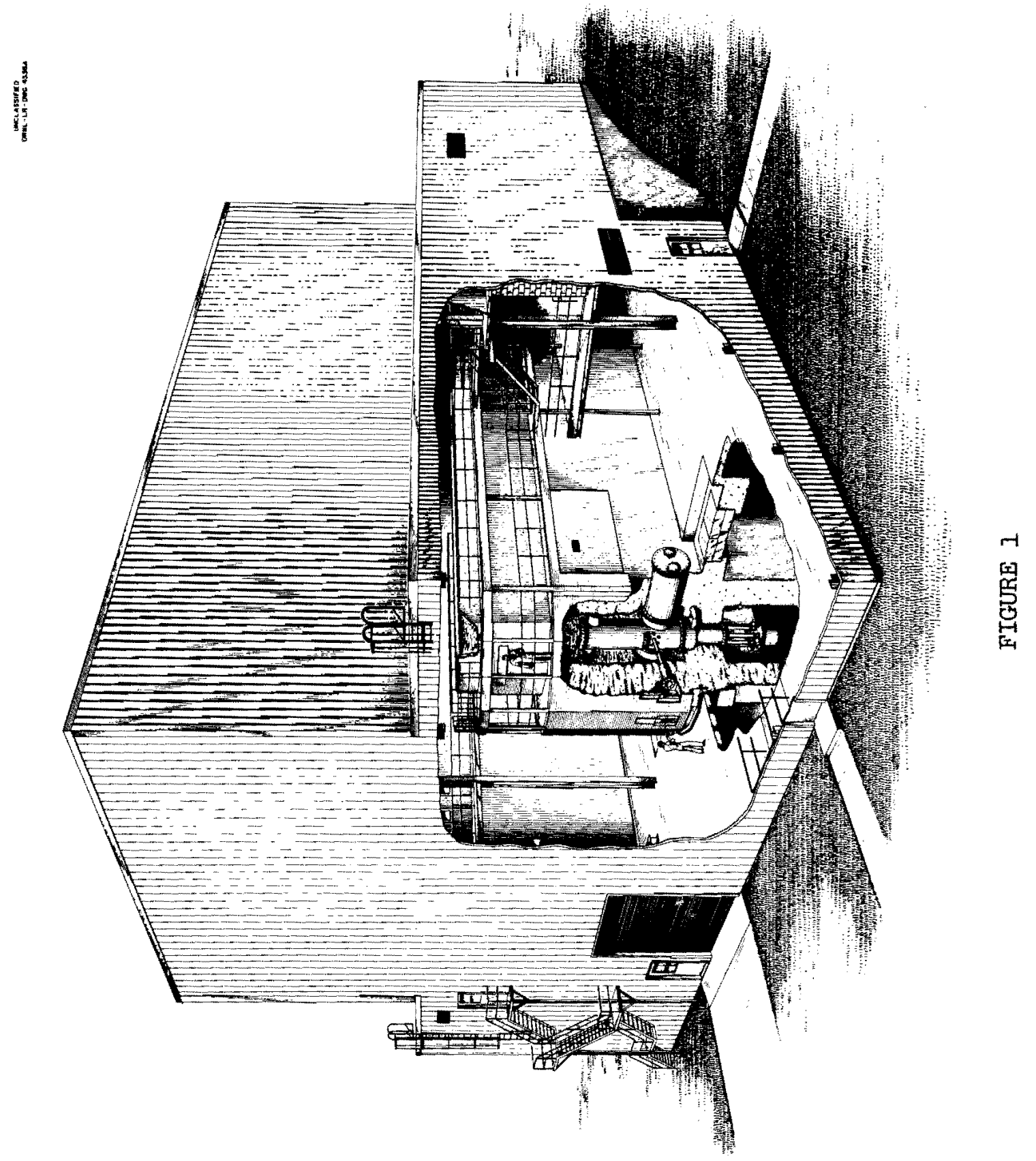


walls. The personnel doors are all provided with standard hydraulic door-closing devices and are normally closed. The truck doors are opened and closed automatically by means of pneumatic devices. The other openings are provided with louvers which may be opened or closed by remotely operated air actuators.

The emergency ventilation system, which is designed to exhaust air from the building at a rate of $6000 \mathrm{cfm}$, derives its draft from equipment located in the stack area (Figure 2). This consists of five electrically driven blowers having a maximum combined capacity of approximately 200,000 cfm and three stand-by steam-driven blowers having a combined maximun capacity of approximately 95,000 efm. Under normal conditions, approximately $120,000 \mathrm{cfm}$ of air is passed up the stack. One electrically driven blower of 40,000-cm capacity and one stand-by steam-driven blower of 60,000 -cfm capacity are connected in such a vay as to provide the 6,000-cfm draft for the ORR building. The remaining capacity is utilized elsewhere in the Laboratory.

Originally, the builoing ventilation system was connected to the stack by means of suitable dampers in such a way that upon actuation of a switch the normal heating and ventilation system was cut off and air was exhausted through the scrubber and to the stack by means of a 29-in. transite duct. Simultaneously the roof fans were shut off, the louvers covering the various building openings closed, and the large truck doors closed--all by remote control.

The scrubber (Figure 3) utilizes a countercurrent flow of $5 \%$ sodium hydroxide solution as a washing agent to remove iodine for the exhaust air. It consists of a $5-x 5-x 53 / 4-f t$ high column of berl 


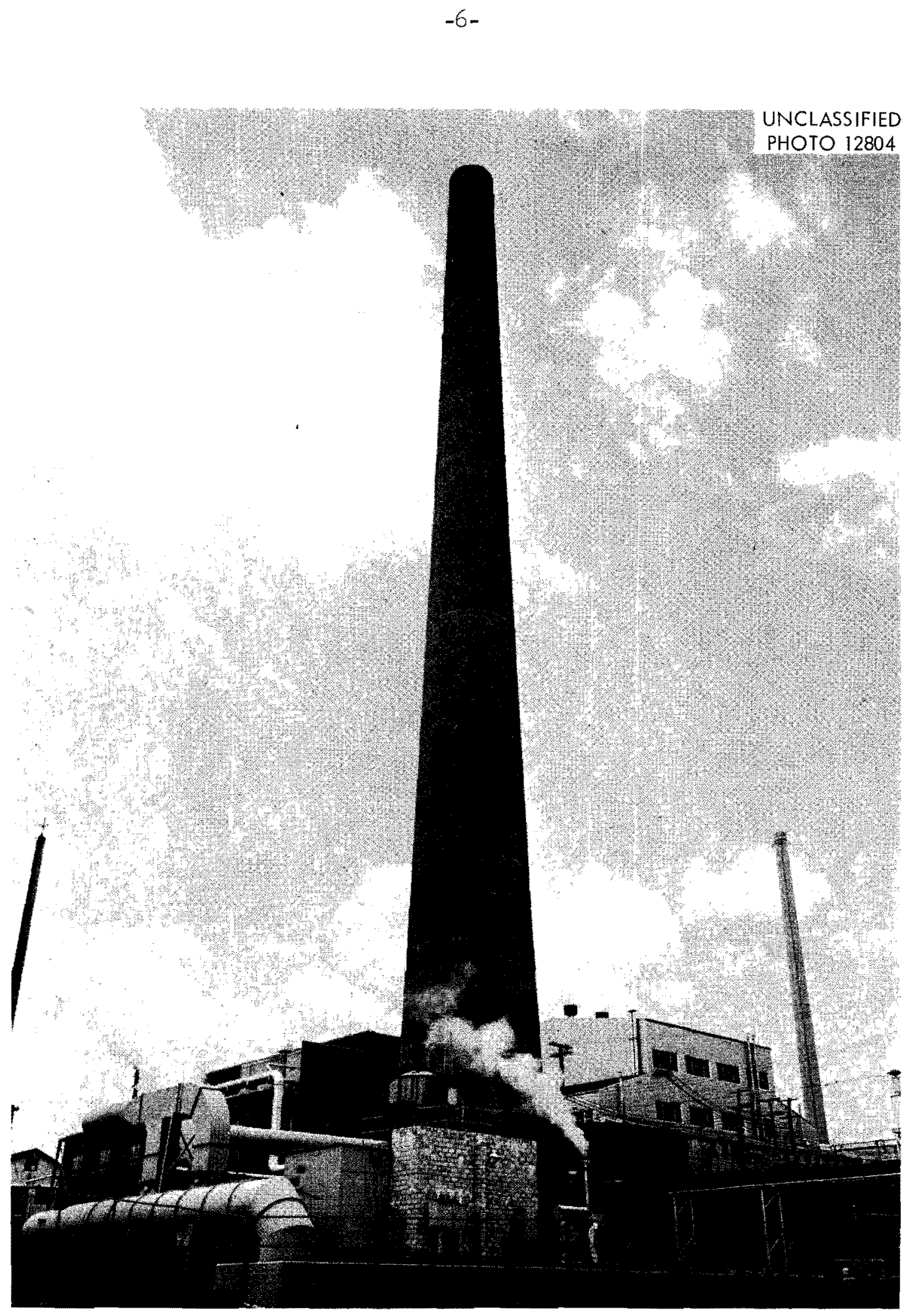

FIGURE 2 
9.

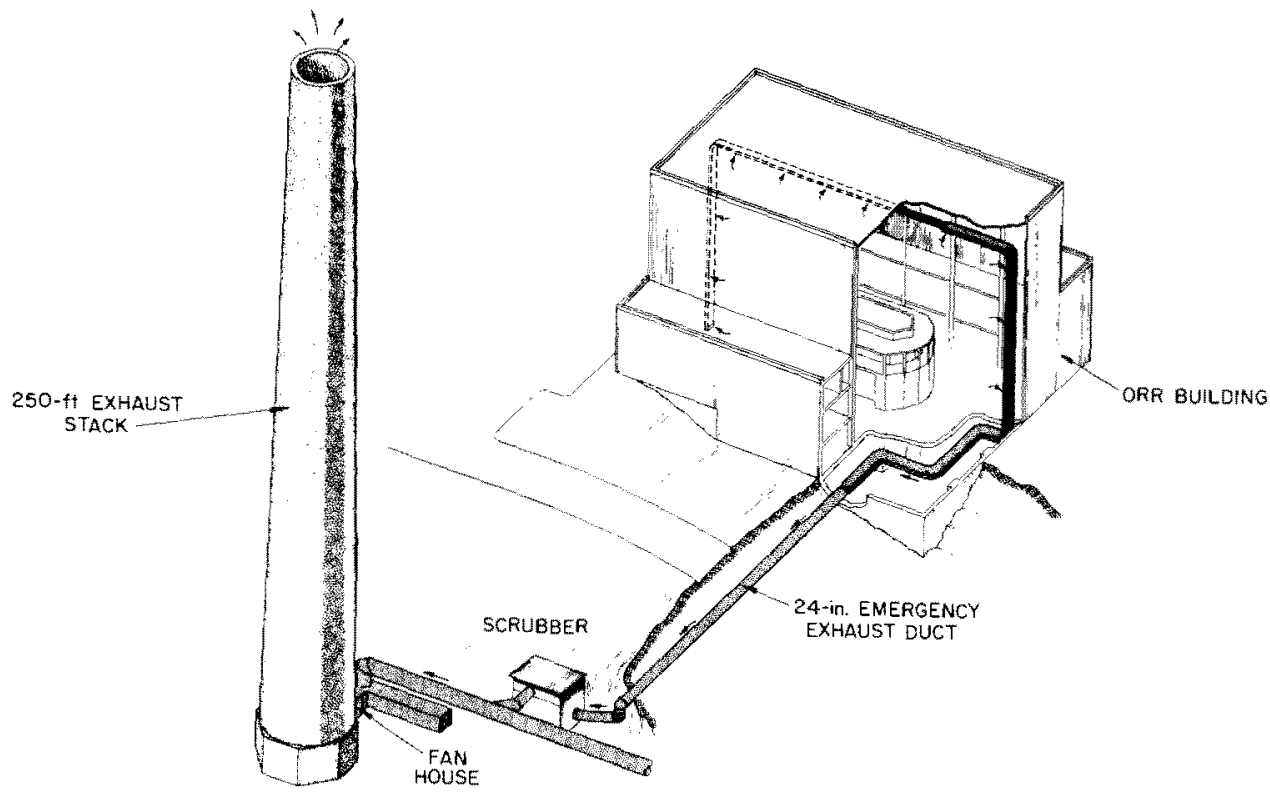

UACLASSIFIED ORNL-LF-OWG $36384 R$

Schematic of ORR Emergency Exhoust System.

,

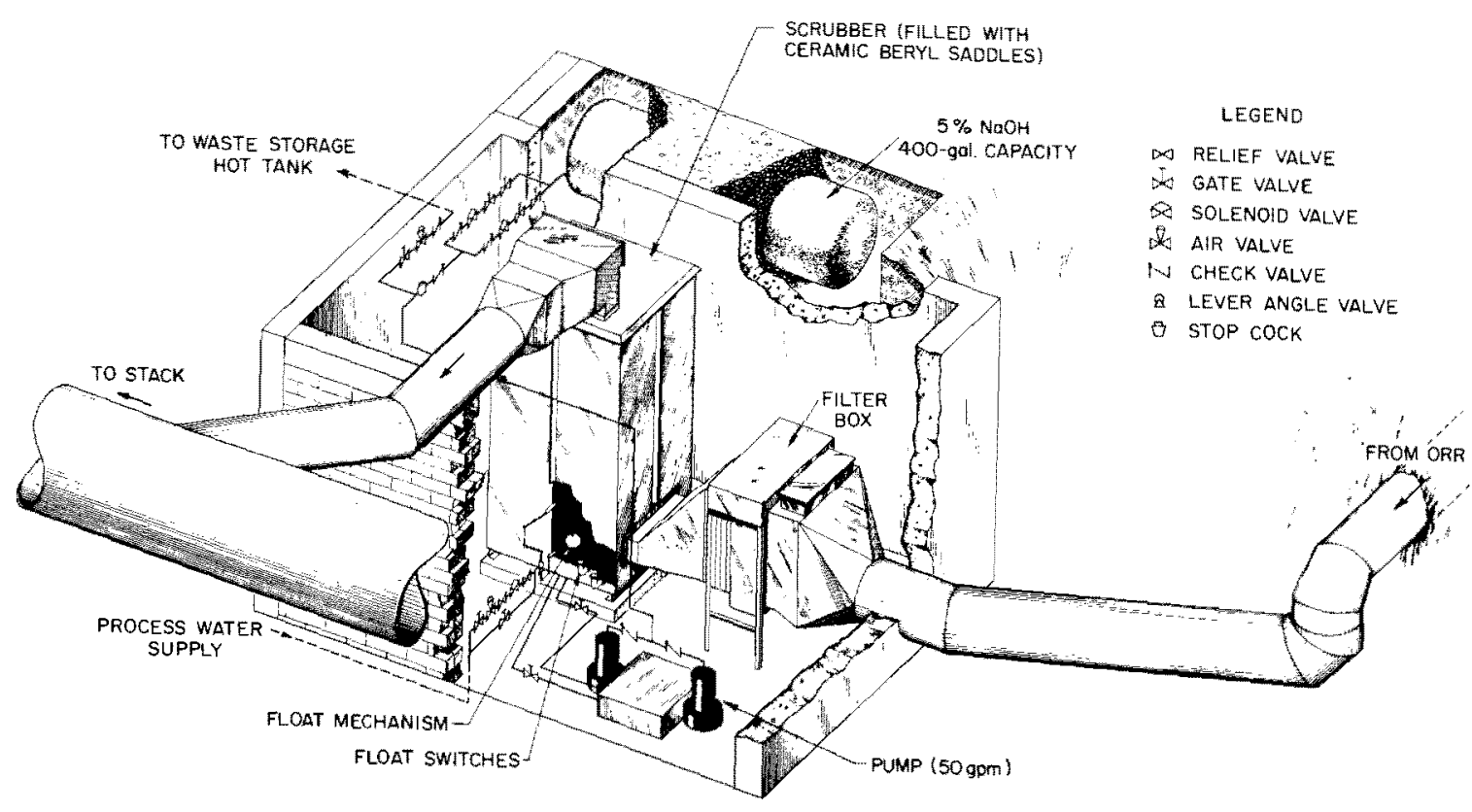

ORR Decontamination Scrubber

FIGURE 3 
saddles over which the caustic solution is pumped. The exhaust air enters the scrubber from below after having passed through an absolute filter rated to remove $>99 \%$ of particles of greater than 0.3 micron in diameter. The air then passes upward through the packed column and into the stack. Caustic solution for the scrubber is stored in a 400-gallon storage tank from which it flows, by gravity, to the sump of the scrubber. A small pump carries the caustic to the distribution heads at the top of the column. Activation of the scrubber is accomplished by means of the same switch which cuts off the normal heating and ventilating equipment.

\section{SURSEQUENT DEVELOPMENTS}

As a result of four years' experience with controlled containment of the ORR, a considerable amount of useful information concerning the design and operation of such a system has been developed. This, in turn, has resulted in a number of modifications to the system. The information can conveniently be divided into two categories; that which is concerned with the conceptual design of the system, and that which relates to the mechanical design and operation of the system components.

Conceptual Design

The original concept was based upon the arbitrary assumption that the only "volatile". fission products are the iodines and noble gases and that it is credible to suppose that an accident could release $100 \%$ of these. After the incorporation of these assumptions into the ORR design concept, a number of developments occurred. The most sienificant of these was the series of "threshold melting" experiments performed in 1959 by G. E. Creek, W. J. Martin, and G. W. Parker. ${ }^{4}$ In these experiments it was found that considerably less than 100\% of the "volatile" 
fission products are released when uranium-aluminum alloy is held at $850^{\circ} \mathrm{C}$ for a short period of time. Moreover, upon reconsideration, an accident which would result in a 100\% core meltdown seems highly unlikely. This latter view has recently been strengthened by the results of the WTR, SL-1, and ETR incidents.5, 6, 7

In addition, in the original dose calculations, all of the iodines were given weight equal to that of the most hazardous isotope; namely, I131. Upon weighting the five iodine isotopes in accordance with their relative hazard ${ }^{8}$, it was found that the internal dose due to iodine isotopes was actually a factor of 5 less than that originally estimated.

Upon incorporating this change into the containment calculation, it is easy to deduce that a $50 \%$ core meltdown (which is now considered to be a conservative estimate) coupled with a $10 \%$ iodine release (somewhat higher than that found by Creek, et al) requires only a factor of 10 decontamination in the scrubber, rather than a factor of 1000 as originally estimated.

Balancing these encouraging results are the facts that upon test, to be described later, the scrubber presently achieves a decontamination factor of only 100 and that the powex level of the ORR, and thus its iodine inventory, has been increased by a factor of 1.5 to $30 \mathrm{MW}$.

More significant are the results of recent fuel-melting experiments by a number of investigators.9, 10, 11, 12 without exception, it was found that at temperatures in excess of the melting point of uranium the amount of iodine released increased rapidly with time at temperature, approaching $90 \%$ of the total as the heating time increased. Thus the assumption of a $10 \%$ release of iodine from the melted portion of the 
fuel appears to be valid only if the accident is such that the fuel remains molten for a very short period of time.

At these elevated temperatures a substantial fraction of the tellurium escapes as do most of the noble gases. Of the other fission products, cesium and ruthenium may be considered to be "semivolatile", being released in quantities of the order of 30 and $1 \%$, respectively. Strontium, barium, and zirconium appear to be nonvolatile in that less than $1 \%$ escapes. ${ }^{12}$ Some typical results are shown in Figures 4 and 5 .

It is worth noting that in many cases these nuclides have a tendency to deposit readily on surfaces. In two of the investigations it was found that filters removed in excess of $90 \%$ of the tellurium, cesium, and ruthenium and more than $50 \%$ of the iodine, strontium, and barium. It seems reasonable, therefore, to assume that if adequate filters are present in the exhaust system the only fission products which need be considered to escape the building are, as was originally postulated, iodine and the noble gases. The latter can be assumed to be $100 \%$ released from the melted portion of the fuel and the over-all iodine release, taking into consideration loss in the duct and filter, to be at most $50 \%$ from the melted portion of the fuel.

Finaliy, it was thought prudent to recalculate the maximum ground concentration resulting from unit aischarge from the stack using more upto-date methods. This calculation was performed, and it was found that an emission rate of 1 curie per minute resulted in a maximum ground concentration of $5 \times 10^{-7} \mathrm{mc} / \mathrm{cc}$. This is to be compared with the value of $3 \times 10^{-7} \mu \mathrm{c} / \mathrm{cc}$ used in the original estimate. 
$\therefore$
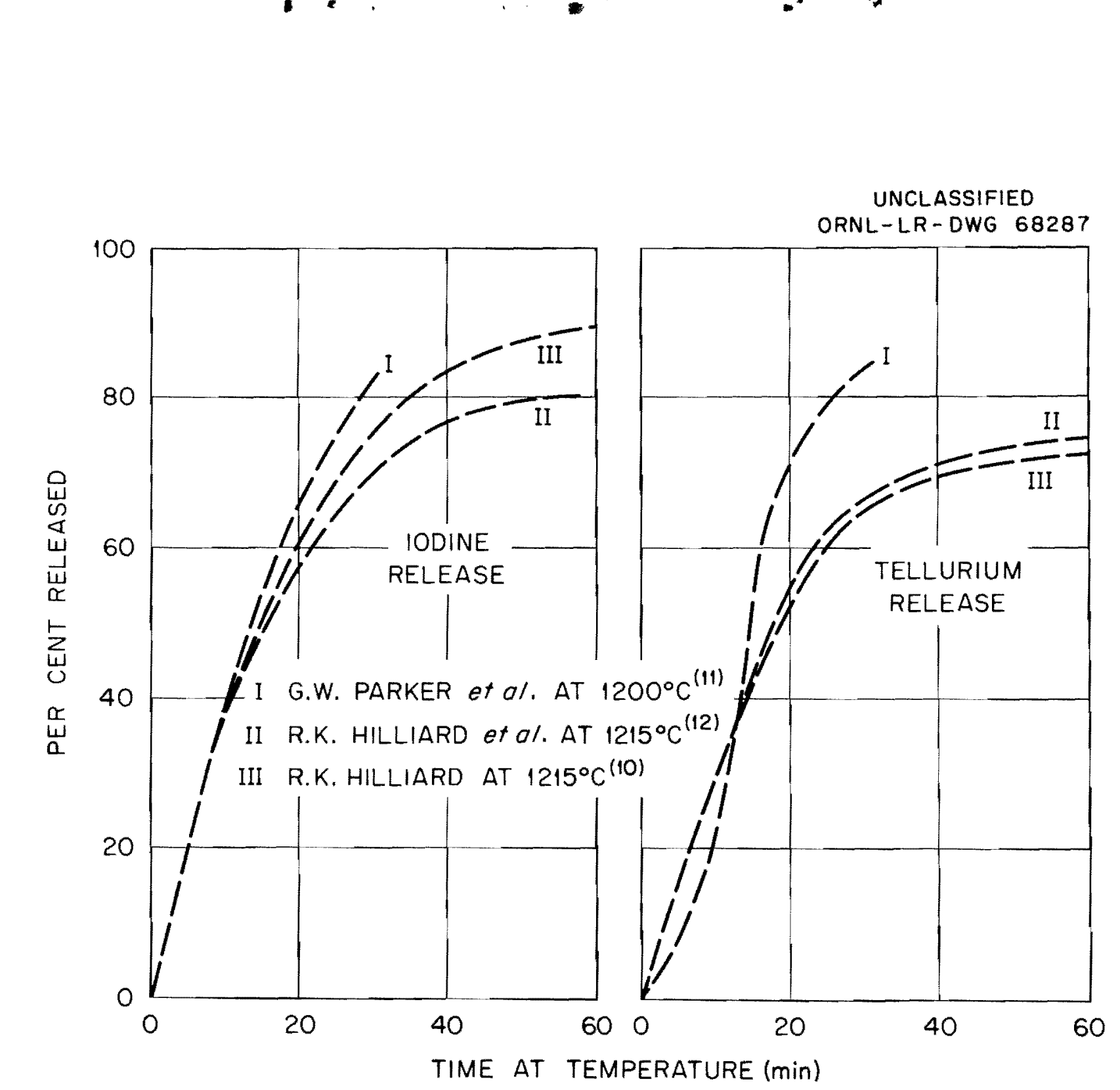

Fission Product Releases.

FIGURE 4 
UNCLASSIFIED
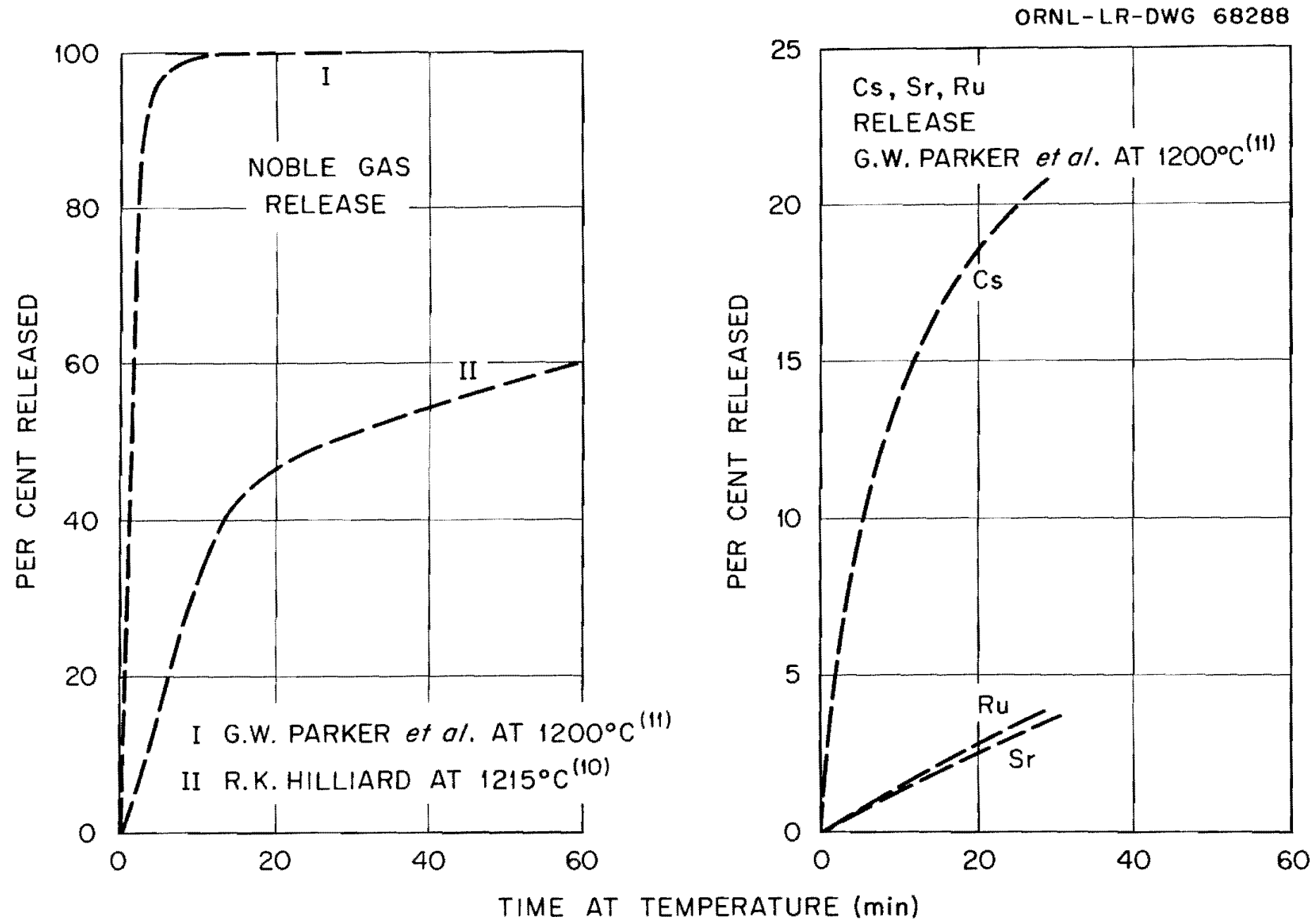

Fission Product Releases.

FIGURE 5 
In summarizing these considerations it is possible to point to three areas in which information must be developed in order to set criteria for the conceptual design of a vapor-containment system similar to that in use at the Oak Ridge Research Reactor.

1. The maximum accident against which protection is to be afforded must be established. This includes an identification of the fission products which escape and the quantity of each to be expected. To determine these quantities some notion of the time at melting temperature is required. In the case of reactors operating at $5 \mathrm{~N}$ w or less, shutdown concurrent with complete loss of water is unlikely to cause extensive melting. With higher powered reactors some melting will occur, and at least some portion of the core may be exposed to melting temperatures for a considerable time. In the case of meltdowns caused by power excursions or local flow blockage, the melting would be expected to be of the "threshold" type unless loss of coolant also resulted from the accident.

2. It seems clear that, for the type of accident described, the iodines are the controlling factor in determining the resultant radiation doses. It is necessary to estimate the magnitude of the doses at various points down wind. In the case of the ORR this was done by means of the so-called "Gaussian Plume" model. 13, 14, 15 The calculation was performed at each point down wind for a number of stability conditions and wind velocities in order to determine the worst average conditions at each point. The highest doses found, regardless of meteorological conditions, were then plotted and are given in Figure 6. The curve has been normalized to the escape of all of the iodines produced in fuel which has been operated for a time long compared with the half life of Il3l at a 


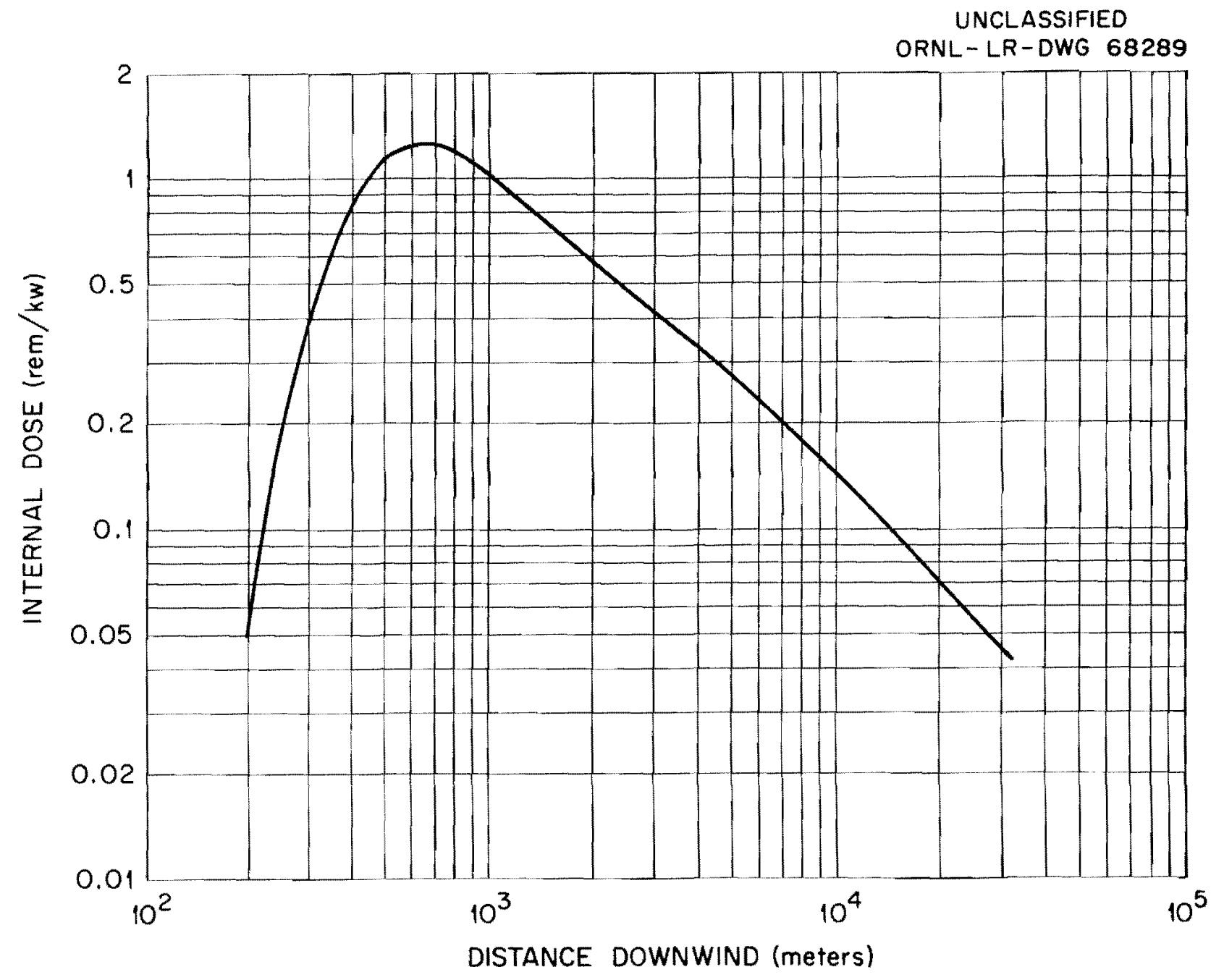

Maximum Internal Dose from lodine as a Function of Distance Downwind.

FIGURE 6 
power level of one kilowatt. It does not represent the result of a single accident at each point but rather the worst condition at each point when conditions are such as to maximize the concentration at that point. Details of the calculation are given in the appendix.

3. After estimating the maximum down wind dose per unit of iodine released, it becomes necessary to determine the decontamination factor required to reduce the maximum dcm wind dose to an acceptable level. In the case of the ORR this acceptable emergency dose was taken to be $25 \mathrm{rem}$ to the thyroid. The decontamination. factor is composed of contributions due to deposition on various surfaces, including the filters, and of removal by the action of the scrubber. The original installation was tested by introducing jodine vapor traced with $I^{13}$ into the duct a few feet ahead of the scrubber. Gas samples were taken simultaneously on both sides of the scrubber and analyzed radiochemically. The decontamination factor was obtained from a comparison of these results and was found to be approximately 100 .

In order to reduce the radiation background, the filters were removed during these tests so that the decontamination factor associated with them was not determined. Moreover, the iodine was passed through only a few feet of the duct so that little credit was taken for deposition in the duct. Currently, another series of tests are planned to determine the decontamination factor of the system. In this series 25minute $I^{128}$, produced by the irradiation of $I^{127}$, will be injected into the duct at the point where it leaves the building. Samples will be taken at various points in the duct, on both sides of the filter, on both sides of the scrubber, and at the stack in order to obtain more definite 
information concerning the decontamination factor under actual operating conditions.

It should be pointed out in connection with this test that the form in which the iodine is present has a profound effect on the ability of any given agency to remove it. Iodine present as a vapor or incorporated with relatively large particles $(>0.3 \mu)$ will be removed by the scrubber and filter; however, iodine present essentially as an aerosol in the form of particles less than a few tenths of a micron in diameter may effectively escape. Thus if the test is performed with iodine vapor it will not reveal the fate of iodine should it be reieased from an accident in the form of an aerosol.

Component Design and Performance

Originally the ORR containment system was virtually a 100\% start-ondemand system. With the exception of the stack blower which is normally a.ways runing, the entire system was put into operation by means of a manual switch located in the control room. Upon closing this switch, the louvers covering the various building openings were closed, the roof fans shut off, the truck doors closed, and the damper opened to the emergency ventilation system thus supplying draft from the stack. In adaition, the scrubber was activated.

It was quickly recognized that such a system provided a great many opportunities for failure, and it has been modified in a number of ways. The damper connecting the emergency ventilation system to the stack is now always open so that the building is constantly kept under draft. Automatic closing of the louvers and truck doors together with shut-off of the roof fans is now accomplisined by means of a radiation-detection 
device located in the building. This device also activates the scrubber. These operations can also be initiated manually.

While it is believed that these modirications greatly decreased the possibility of failure, there are several areas in which greater reliability is desired. To appreciate this it is necessary to realize that the system consists of two types of components: high-performance components which must work properly or the system will not provide containment, and low-performance components which may fail to some extend without producing disasterous results.

Of the high performance components, the most important is the stack draft. Since this is now continuously connected to the building and since the reactor is required by administrative edict to be shut down if the draft fails, it is believed that this portion of the system is sufficiently reliable. The other component which must work is the circuit which shuts down the roof fans. These fans exhaust air directly to the atmosphere at roof elevation and must be prevented from doing so in the event of a fission-product release within the building.

Complete closure of all the building openings is desirable but not absolutely necessary. In fact it is absolutely necessary for sufficient air to leak into the building to replace that removed by the blowers. One of the advantages of controlled containment is that it can be made to work even though there is a hole in the building. There is qualitative evidence to indicate that containment is achieved even with one of the large truck doors open.

A considerable amount of confusion has arisen over this point. The criterion for leakage is "when the system is in operation all leakage 
must be into the building," not "there shall be no leakage". To this end it is currently proposed to test the containment using anemometers located in small openings in the building wall rather than by pressuredifferential measurements.

It is not clear at present whether the scrubber must be a highperformance component. It is obvious, however, that if the scrubber, when operating properly, removes a large fraction of the iodine it is highly desirable for it to be in working condition. On the other hand, if the contemplated tests indicate that a large enough decontamination factor is obtained from deposition in the duct and filter alone to reduce the dose rates down wind to a tolereble level, the scrubber could be considered to be an intermediate-performance component. That is, its failure would not result in a catastrophe; but its proper operation would reduce a serious accident to a triviality.

Currently, action is being taken to increase the reliability of those components which are considered essential. Primarily, this has taken the form oi more reliable circuitry and multiple devices, such as pumps and detectors, for the purpose of actuating the system. Difficulty with the scrubber has centered around failure of the circulating pumps to start and malfunction of float switches. Consideration is being given also to the use of sodium thiosulfate as a washing agent. There is some reason to believe that water only mey be sufficient to provide the required decontamination. If this proves true, the scrubber will be operated continually using water only. In any case, it is anticipated that the scrubber vill eventually be replacea by a charcoal-bed filter which will then be continuously "on the line". In addition to added reliability, 
this is needed in order to provide greater pressure differential in equipment cells, hot cells, and other containment structures inside the ORR building.

\section{CONCLUSION}

It is hoped that the foregoing remarks have shed some light on the basic considerations associated with the ORR type of vapor containment. There remain, of course, many unknowns, not the least of which is an understanding of the actual behavior of the fission products following release from melted fuel. Moreover, little is known of the temperature distributions to be expected in a reactor core following loss of coolant. These and other questions, it is hoped, will be solved in the future. Nevertheless, it is believed that through the use of conservative approximations it is possible to demonstrate that controlled containment is a valuable technique for many applications. 
1. T. E. Cole, J. P. Gill, The Oak Ridge Research Reactor, A General Description, ORNL-2240 (2957).

2. F. T. Binford, T. J. Burnett, A Method for the Disposal of Volatile Fission Products from an Accident in the ORR, ORNL-2086 (1956).

3. D. R. Purdy, R. F. Meyers, Calculations for Unit Emissions of AirBorne Contaminants (1954) Unpublished.

4. G. E. Creek, W. J. Martin, G W. Parker, Experiments on the Release of Fission Products from Molten Reactor Fuels, ORNI-2616 (1959).

5. Westinghouse Testing Reactor Staff Report, Report on WRT Fuel Element Failure April 3, 1960, WRT-49.

6. Nucleonics News, Nucleonics 19, (2), 17-21, (Feb., 1961).

7. F. R. Keller, Results of a Flow Restriction in ETR Fuel Elemerts, Delivered at Conference on Lightwater-Moderated Reactors, ORNL, June, 1962.

8. T. J. Burnett, ORNL Health Physics Div., Private communication, Jan., 1962.

9. S. J. Rodgers, G. E. Kennedy, Fission Product Release During a Simulated Meltdow of PWR Type Core, MSA Research Corp. Tech. Rep. 63 (1958).

10. R. K. Hilliard, Fission Product Release from Uranium Heated in Air, HW-60689 (1959).

11. G.W. Parker, G. E. Creek, W. J. Martin \& C. J. Barton, Fuel Element Catastrophe Studies: Hazards of Fission Product Release from Irradiated Uranium, ORNL CF-60-6-24 (1960).

12. R. K. Hilliard, C.E. Linderoth, A. J. Scott, "Fission Product Release from Overheated Uranium - A Laboratory Study", Health Physics $I$ $1-10,(2961)$.

13. F.A. Giffora, Jr., "The Problers of Forecasting Dispersion in the Lower Atmosphere", Nuclear Safety $\stackrel{I}{=}$ (3), (March, 1960).

14. F.A. G.fford, Jr., "Atmospheric Dispersion", Nuclear Safety 2 (2), (Dec., 1960).

15. F.A. Gifford, Jr., "Use of Routine Meterorological Observations for Estimating Atmospheric Dispersion", Nuclear Safety $\cong$ (4), (July, 1960). 


\section{$-21-$}

\section{APPENDIX}

\section{Iodine-Dose Calculation}

The accident under consideration is that in which some fraction of the volatile fission products is released in a closed building from which the air is continuously removed and exhausted through a tall stack. In the following calculation only the internal dose due to the five iodine isotopes is considered, although a similar calculation may be made for any of the other fission products. The following specific assumptions are made.

1. The release of the fission products into the building is instantaneous.

2. There is immediate and unform mixing in the building, both of the released fission products and the incoming air, so that at any instant the concentration is everywhere the same.

3. The volume and density of the air in the building remains constant; however, sufficient draft is maintained so that all the air removed passes up the stack and is replaced by clean air which leaks in.

The concentration of the various iodine isotopes in the stack plume is now sought as a function of distance down wind.

\section{Stack Emission Rate}

Consider a building of volume $V\left(\mathrm{~m}^{3}\right)$ from which air is exhausted at a constant rate $F(\mathrm{~m} 3 / \mathrm{min})$, and into which fresh air is entering at the same rate. It is convenient to express the exhaust rate in terms of fractional building volume removed per unit time. Thus a specific exhaust rate $D\left(\mathrm{~min}^{-1}\right)$ may be defined by the relation 
$F \equiv D V$

If at a time $(\min ) t=0$ a quantity of radioactive material $A^{\circ}$ (curies) is suddenly released into the building, the initial concentration will be

$\xi(0)=A^{\circ} / V \quad\left(\right.$ curies $\left./ m^{3}\right) *$

This concentration will be altered in two ways--first, by radioactive growth and decay and, second, by dilution and removal due to the air sweep through the building. For the iodine isotopes the only radioactive process is simple decay. Hence, the concentration of each of the iodines is governed by an equation of the type

$\dot{\xi}(t)=-(\lambda+D) \boldsymbol{\xi}(t), \quad \boldsymbol{\xi}(0)=A^{\circ} / V$

where $\xi(t)$ is the concentration in curies $/ \mathrm{m}^{3}$ at time $t$ and $\lambda$ is the decay constant $\left(\min ^{-1}\right)$. The solution of this equation is

$\xi(t)=\frac{A^{O}}{V} e^{-(\lambda+D) t} \quad\left(\right.$ curies $\left./ m^{3}\right)$

Given this result, it follows that the emission rate from the building is just $F \xi(t)=V D \xi(t)$ so that, if emission from the stack is taken to be simultaneous with emission from the building, the rate of emission from the stack, denoted by $E(t)$, becomes

$E(t)=D e^{-D t_{A} e-\lambda t} \quad$ (curies/min)

\section{Atmospheric Concentration}

The dose rates which result because of the emission of the iodine isotopes from the stack depend upon the concentrations produced in the atmosphere at the point of exposure. These concentrations are governed not only by the emission rate but also by the stack height, the wind speed, and other meteorological parameters which determine the rate of

* Note that 1 curie $/ \mathrm{m}^{3}$ is numerically equa? to $1 \mu / \mathrm{cc}$. 


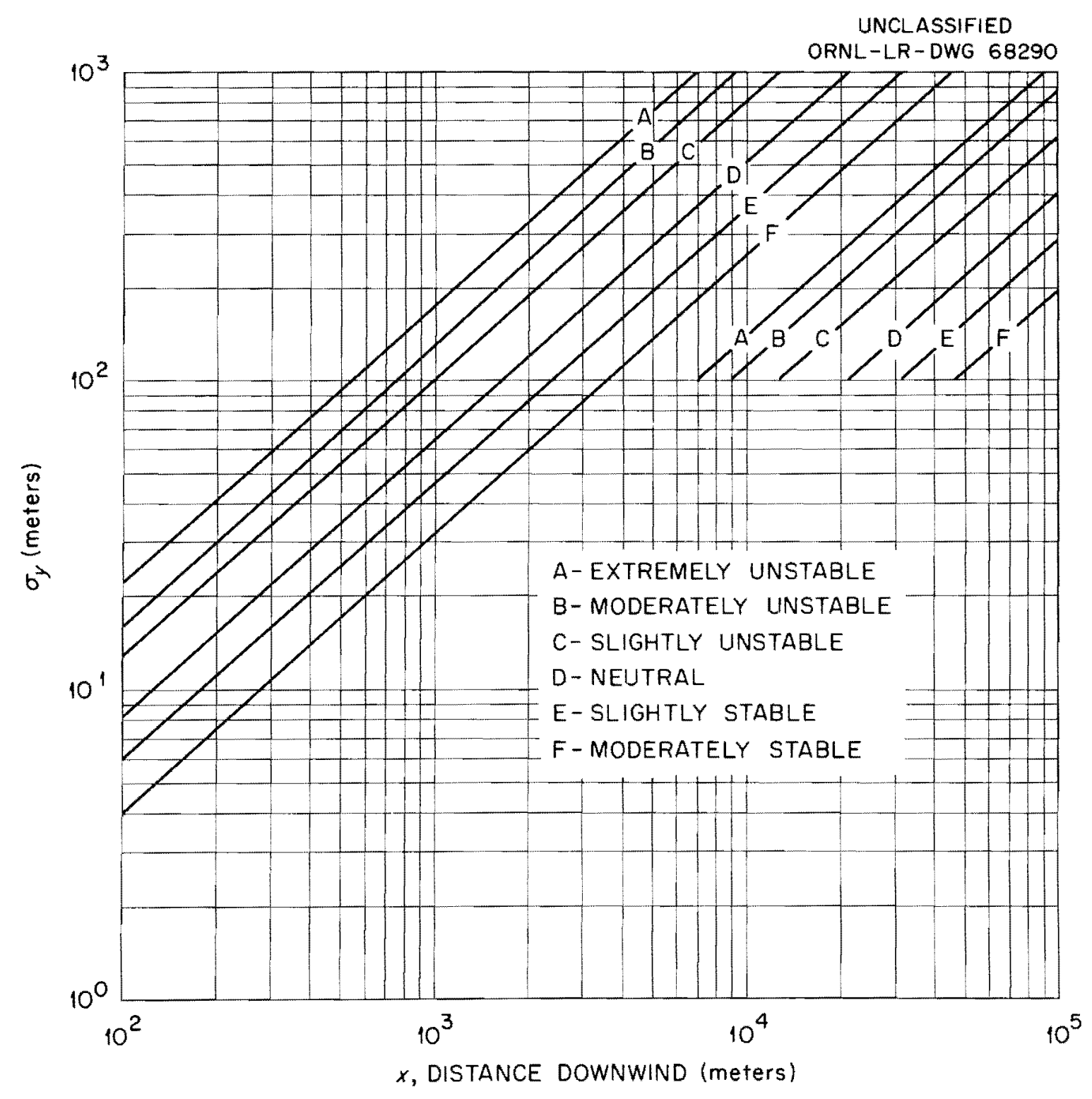

Horizontal Dispersion Coefficient.

FIGURE ii 
where

$$
\begin{array}{ccc}
\mathrm{h}=\text { actual stack height }(\mathrm{m}) & \mathrm{v}_{\mathrm{s}}=\text { exhaust velocity }(\mathrm{m} / \mathrm{min}) \\
\mathrm{d}=\text { oriface diameter }(\mathrm{m}) & \mathrm{u}=\text { wind speed }(\mathrm{m} / \mathrm{min}) \\
\mathrm{q} & =\text { heat input }(\mathrm{cal} / \mathrm{sec})
\end{array}
$$

The source term, $Q$, in equation ( 4 ) is a constant and must be modified in order to make the equation apply to a source which varies with time. Now, in equation (3) the factor $e^{-\lambda t}$ which involves radioactive decay will continue to effect changes in the concentration regardless of whether the isotope is in the building or not. On the other hand, the factor $e^{-D t}$ is effective only during the dilution process in the building. If an increment of gas, released in the building at time zero, reaches a point $x$ down wind at time $t$, it must have been emitted from the stack at time $t-x / y$, where $u$ is the wind speed. It follows that at a distance $\mathrm{x}$ down wind the appropriate source term will be

$$
\begin{array}{ll}
Q(x, t, u)=D e^{-D(t-x / u)_{A} e^{-\lambda t}} & t \geq x / u \\
Q(x, t, u)=0 & t<x / u
\end{array}
$$

Here, $t$ is the time at which the observation at $x$ is made, measured from the time of release in the building; and $Q$ is zero for times less than $\mathrm{x} / \mathrm{u}$ because it takes just that long for the released gas to reach a distance $\mathrm{x}$ down wind.

$$
\begin{array}{ll}
\text { Upon setting } & t \geq x / u \\
\Psi(x, h, u) \equiv \frac{\exp \left(\frac{D x}{u}-\frac{h^{2}}{2 \sigma_{z} z}\right)}{\pi u \sigma_{y} \sigma_{z}} & t \leqslant x / u
\end{array}
$$

the ground concentration can be written

$x(x, h, u, t)=D A^{\circ} e^{-D t} e^{-\lambda t} \psi(x, h, u) \quad(\mu \mathrm{c} / c c)$ 
diffusion and dilution of the stack plume.

Because of the variability of meteorological conditions, the prediction of atmospheric behavior cannot be accomolished with precision: however, Gifford* has recommended that the generalized Gaussian-plume formula is most often appropriate for such calculations. According to this relation, the ground concentration $X$ at a point $x$ meters down wind Prom a stack of effective height $h_{e}(m)$ is given by

$x(x, h, u)=\frac{Q}{\pi u \sigma_{y} \sigma_{z}} e^{-h^{2} e / 2 \sigma_{z}^{2}}$

Here, $x(x, h, u)$ is expressed in $\mu c / c c$ if $Q$ is the emission rate in curies/min, $u$ is the wind speed in $\mathrm{m} / \mathrm{min}$, and $\sigma_{y}, \sigma_{z}$ are the horizontal and vertical dispersion coefficients, respectively, expressed in meters. Values of $\sigma_{y}$ and $\sigma_{z}$ have been found experinentally for various stability couditions and are given in Figures i and $i i$.

The effective stack height, $h_{e}$, is the sum of the actual stack height, $h$, and the height to which the effluent plume rises above the stack orifice due to its initial velocity and buoyancy. There is little agreement among meteorologists concerning the best method of estimating the rise of the plume; however, a relation proposed by Holland** appears to give reasonable agreement with observation. According to Holland 's formula

$h_{e}=h \frac{1.5 V_{S} d+2.45 \times 10^{-13} 2}{u}$ (meters)

*F. A. Gifford, Jr., Nuclear Safety $\cong$ (4) (June 1961).

**J. Z. Holland, A Meteorological Survey of the Oak Ridge Area ORO 99 (1953). 


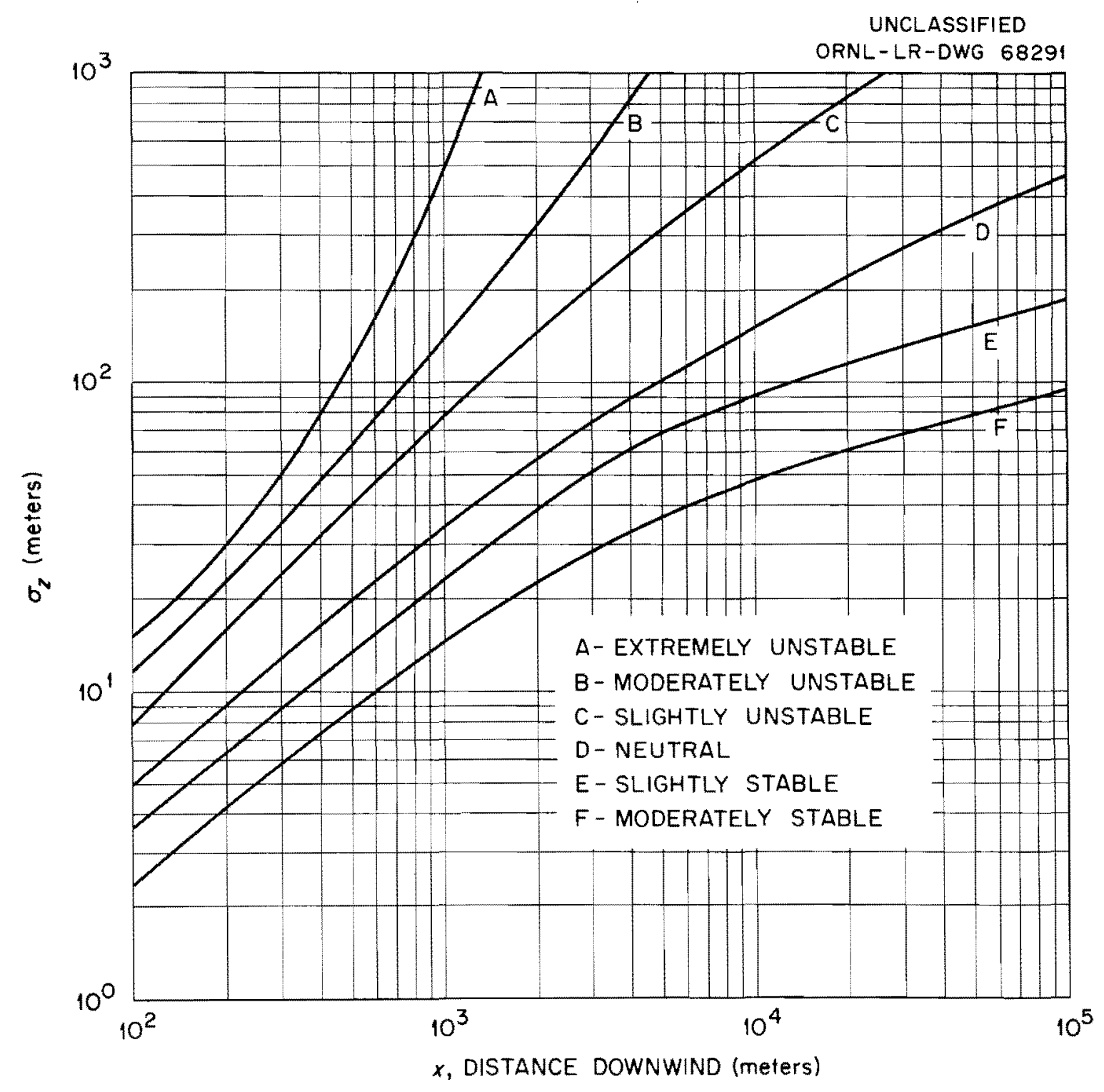

Vertical Dispersion Coefficient.

FIGURE i 
Dose Calculation

The five iodine isotopes of interest are $I^{131}, I^{132}, I^{133}, I^{134}$, and I35. Burnett* has calculated the total dose to the critical organ, in this case the thyroid, which results from the inhalation of a unit quantity of each of these isotopes. Moreover, the average breathing rate is taken to be $3 \times 10^{4} \mathrm{cc}$ per minute. Thus, if $W_{i}$ is the dose delivered in rem per inhaled microcurie due to inhalation of the i'th isotope, the total dose delivered by the $i^{\prime}$ th isotope as a result of inhalation of air having a concentration $x_{i}$ for a time $\tau$ will be $I_{i}(\tau)=3 \times 10^{4} \mathrm{w}_{i} \int_{0}^{\tau} \mathrm{x}_{i}(\mathrm{x}, \mathrm{h}, \mathrm{u}, \mathrm{t}) \mathrm{dt}$ and the total dose is obtained by surmation over all five of the iodine isotopes. Thus the total dose delivered to the thyroid of a person who remained at the point $\mathrm{x}$ down wind from some time prior to the accident until a time $\tau$ following the accident and measured from $\tau=0$ at the time of the accident becomes $I(t, x, h, u)=3 \times 10^{4} D \psi(x, h, u) \int_{0}^{\tau} e^{-D t}\left(\sum_{i=1}^{5} w_{i} A_{i}^{0} e^{-\lambda_{j} t}\right) d t$

The maximum value of $I(t, x, h, u)$ occurs when $\tau \rightarrow \infty$. Upon substituting for $\psi(x, h, u)$ its value from (7) and integrating (9) from zero to infinity, the maximum internal lodine dose is found to be $I_{\infty}(h, u, x)=\frac{3 \times 10^{4}}{\pi u \sigma_{z}} e^{-h^{2} / 2 \sigma^{2}} \sum_{i=1}^{5} \frac{W_{i} D}{D+\lambda_{i}} A_{i}^{0} e^{-\lambda_{i} x / u}$ rem

Values of $A_{i}^{O}, W_{i}$, and $\lambda_{i}$ for the various iodine isotopes are given in Table $I$.

*T. J. Burnett, ORNL Health Physics Division, Private Communication, (Jan., 1962). 
Table 1. Parameters for Calculating Iodine Dose

\begin{tabular}{llcc}
\hline INuclide & $\lambda_{i}\left(\mathrm{~min}^{-I}\right)$ & $\mathrm{A}_{\mathrm{i}}^{0}(\text { curies } / \mathrm{kw})^{\mathrm{a}}$ & $\mathrm{W}_{i}^{\mathrm{b}}($ rem/inhaled $\mu \mathrm{c})$ \\
\hline $\mathrm{I}^{131}$ & $5.98 \times 10^{-5}$ & 24.45 & 1.484 \\
$\mathrm{I}^{132}$ & $4.81 \times 10^{-3}$ & 37.10 & 0.054 \\
$\mathrm{I}^{133}$ & $5.55 \times 10^{-4}$ & 59.02 & 0.399 \\
$\mathrm{I}^{134}$ & $1.32 \times 10^{-2}$ & 71.67 & 0.025 \\
$\mathrm{I}^{135}$ & $1.73 \times 10^{-3}$ & 64.08 & 0.123 \\
\hline
\end{tabular}

asaturation assumed

brotal integrated dose to the thyroid

Equation (10) gives the upper limit of the dose received at a point $x$ under given stability conditions and wind speed. What is really sought is the maximum value that $I_{\infty}$ can take at each down-wind point. Thus it is necessary to maximize equation (10) with respect to the wind speed for each stability condition at each point where its value is sought. The maximum of the se maxima then represents the upper limit of the dose to be expected at that point. In carrying out this operation it must be remembered that $h$ is itself a function of $u$ given in equation (5). 


\title{
DISTRIBUTION
}

\author{
1-200. J.A. Cox \\ 201. Document Reference Library \\ 202-203. Central Research Library \\ 204-206. Laboratory Records \\ 207. ORO \\ 208-222. Division of Technical Information Extension
}


.

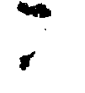

